\title{
Upaya Mewujudkan Wisata Edukasi di Kampung Tulip Bandung
}

\author{
Hary Hermawan, Erlangga Brahmanto, Rahmat Priyanto, Musafa, \\ Suryana
}

STP ARS Internasional Bandung, haryhermawan8@gmail.com

\begin{abstract}
Abstrak
Fenomena aktual dilapangan membuktikan bahwa pengembangan Kampung Tulip belum cukup representatif sebagai wisata bertema edukasi Budaya Belanda. Walaupun beberapa wahana telah dibangun menyesuaikan rumah-rumah khas Negeri Belanda, tetapi aktifitas wisata bernuansa edukatif belum begitu terlihat selama masa observasi di lapangan. Oleh karena itu, kegiatan pengabdian masyarakat difokuskan pada pemberdayaan untuk peningkatan tata kelola destinasi wisata edukasi Kampung Tulip. Langkah implementatif yang telah dilakukan meliputi : (1) Menggali akar permasalahan dalam pengembangan destinasi wisata Kampung Tulip melalui observasi dan wawancara dengan pengelola; (2) Memberikan rekomendasi pengelolaan melalui seminar seminar dan pelatihan pengelolaan wisata edukasi dan pariwisata berkelanjutan kepada pengelola destinasi wisata Kampung Tulip; (3) Penyediaan buku panduan pengembangan wisata edukasi Kampung Tulip.
\end{abstract}

Kata Kunci : pariwisata edukasi, kampung tulip, perencanaan pariwisata

\begin{abstract}
Abstrac
The actual phenomenon in the field proves that the development of Kampung Tulip has not been representative enough as a themed education of the Netherlands Culture. Although some of the rides have been built to match the typical homes of the Netherlands, but the activities and educational nuances have not been visible during the observation period in the field. Therefore, community service activities focused on empowerment to improve the educational tourism governance in the destinations of Tulip Village. Implementative steps that have been carried out include: (1) Exploring the core of the problem in developing Tulip Village through observation and interviews with managers; (2) Providing management recommendations through seminar seminars and training on educational tourism and tourism sustainable management to the managers of Tulip Village; (3) Provision of guidance book for educational tourism development in Tulip Village.
\end{abstract}

Keywords: educational tourism, kampung tulip, tourism planning

\section{Pendahuluan}

Pariwisata adalah salah satu industri yang paling berpotensi untuk dikembangkan di Idonesia, mengingat semakin meningkatnya permintaan produk wisata di Indonesia dari tahun ke tahun (Statistik Kepariwisataan, 
2015). Pariwisata merupakan salah satu kegiatan ekonomi yang dinamis dalam menciptakan perubahan ekonomi, diantaranya : diversifikasi ekonomi dan masalah industrialisasi (Yahya, 2015).

Pariwisata menjadi pilar proses pembangunan, karena merupakan salah satu kegiatan ekonomi yang dominan dalam kerangka pembangunan ekonomi (Wijayanti, 2017). Pengembangan pariwisata di suatu daerah yang dikelola dengan baik terbukti mampu memberikan kontribusi yang signifikan bagi pembangunan daerah. Pariwisata terbukti memberi dampak positif bagi kehidupan ekonomi masyarakat seperti : menciptakan peluang kerja baru, meningkatkan kesempatan berusaha, meningkatkan pendapatan masyarakat lokal, meningkatkan pendapatan daerah melalui retrubusi dan pajak dan lain sebagainya (Hermawan, 2016).

Angka statistik perkembangan kenaikan kunjungan wisatawan dari tahun ke tahun menggambarkan peluang yang sangat potensial bagi pengembangan usaha destinasi wisata. Akan tetapi, otonomi daerah memberikan kewenangan kepada masing-masing kabupaten/ kota menimbulkan persaingan bauran produk yang tidak terspesialisasi (Prihatno, 2010). Sehingga produk-produk yang ada saat ini cenderung monoton, daya tarik wisata yang ditawarkan cenderung itu-itu saja, akibatnya banyak destinasi wisata yang kurang laku di pasar wisata.

Fenomena di lapangan, beberapa pengelola destinasi wisata di Kota Bandung mulai menyadari adanya kejenuhan produk-produk wisata seperti diatas. Oleh karena itu, beberapa pengelola mulai berinisiatif untuk menyajikan konsep wisata yang berbeda dari sebelumnya. Salah satu konsep kegiatan wisata yang masih baru adalah destinasi taman bertema edukasi seperti yang dirintis oleh pengelola destinasi wisata Kampung Tulip.

Taman bertema atau theme park merupakan konsep atraksi berupa wahana hiburan di suatu lokasi yang didekorasi dan didesain untuk mencerminkan satu tema tertentu (Lukas, 2008). Taman bertema adalah "tempat" otentik yang menggantikan kekuatan hyperspace yang abstrak dan ageographical Cyburbs dan secara imagistical dari kenyataan yang lebih dari yang nyata (Matthews \& Boyns, 2001). Penyelenggaraan taman bertema telah diatur dalam Undang-Undang Nomor 10 Tahun 2009, Pasal 17 Ayat 2 G tentang penyelenggaraan kegiatan hiburan dan rekreasi dengan subjenis usaha taman Bertema.

Menurut Lukas (2008), taman bertema dapat dibedakan menjadi beberapa jenis yaitu:

1. Adventure park atau extreme park, berciri khas petualangan seperti arung jeram, panjat tebing

2. Futurism (teknologi dan kecanggihan), tema kecanggihan atau teknologi yang diangkat

3. International, ciri khas replika bangunan-bangunan dunia

4. Nature (alam), berciri khas hewan, pemandangan indah, laut, taman, flora

5. Fantasy (dunia maya), mempunyai ciri khas animasi, tokoh kartun, pertunjukan sulap, taman bermain anak 
6. Movies (film), tema ini jelas mengangkat sebuah film khususnya layar lebar ke dalam sebuah taman bertema.

7. Underwater atau waterpark (Rekreasi air)

8. Sejarah dan Budaya, tema ini berisikan sejarah dan budaya dari negara sendiri atau negara lain.

Pengembangan destinasi merujuk pada taman bertema, hendaknya mewujudkan kesemuaannya, sebagai tempat suatu simulasi. Taman bertema memiliki 6 karakteristik yaitu sebagai berikut :

1. Theme park as oasis (sebagai sumber ketenangan), taman bertema menciptakan rasa ketenangan seakan manusia berada di dunia lain yang lebih indah

2. Theme park as land (sebagai dunia impian), taman bertema diidentikkan dengan dunia impian.

3. Theme park as machine (sebagai mesin wahana), taman bertema sendiri adalah sebuah mesin besar; satu yang tersusun dari bermacam kendaraan, peralatan mekanik, subsistem, proses dan pertunjukkan yang menjadikannya sebagai sistem yang fungsional.

4. Theme park as show (sebagai pertunjukan), arsitektur selalu dipertunjukkan tapi jika berkaitan dengan taman bertema, pertunjukan adalah fungsi utamanya.

5. Theme park as text (sebagai bacaan/cerita), saat taman bertema menjadi sebuah bacaan, penceritaan menjadi berlipat ganda, penulisnya tidak lagi sebagai bosnya dan seseorang yang menjadi pusat perhatian dulunya, tapi sebagai taman bertema itu sendiri

6. Theme park as brand (sebagai merk), pada zaman ini perubahan yang paling signifikan dari taman bertema berkaitan dengan merk.

Berdasarkan jenisnya, Kampung Tulip merupakan taman bertema yang diupayakan untuk menjadi taman sejarah dan budaya, merujuk pada teori Lukas. Sedangkan jika ditinjau dari segi karakteristik, Kampung Tulip merupakan taman sebagai sebuah pertunjukan benda-benda khas budaya belanda sebagai daya tarik (theme park as show). Budaya Belanda berada di Bandung merupakan sebuah keunikan yang diharapkn mampu menjadi motivasi wisatawan untuk berkunjung (Sammeng, 2001; Darsoprajitno, 2002); Kampung tulip juga merepresentasikan sebuah brand, bunga tulip diasosiasikan dengan budaya belanda (theme park as brand). Branding yang tepat berguna untuk menarik konsumen agar menggunakan produk yang ditawarkan dan juga mempertahankan eksistensi dari suatu brand (Hasan, 2013). Penggunaan brand pada suatu destinasi wisata dimaksudkan sebagai pembeda atau ciri khas dari produk wisata lainnya (Assauri, 2012). Selain itu, Kampung Tulip berpeluang untuk dapat dikembangkan lagi dengan menginterprestasikan untuk menjadi karakteristik-karakteristik lainya. Sedangkan pengelola sendiri ingin mewujudkan Kampung Tulip sebagai taman bertema edukasi.

Akan tetapi, fenomena aktual dilapangan membuktikan bahwa pengembangan Kampung Tulip belum cukup representatif sebagai wisata bertema edukasi Budaya Belanda. Walaupun beberapa wahana telah dibangun menyesuaikan rumah-rumah khas Negeri Belanda, tetapi 
aktifitas wisata bernuansa edukatif belum begitu terlihat selama masa observasi di lapangan. Padahal dalam kegiatan taman bertema edukasi, wahana permainan maupun fasilitas pendukung lainnya yang tersedia hendaknya tidak hanya berfungsi sebagai hiburan semata, tetapi diharapkan mengandung unsur edukasi sesuai dengan konsep atau tema yang diangkat (Kusumawardani \& Hermawan, 2017).

Telah menjadi pengetahuan umum bahwa kunci sukses pengembangan destinasi wisata terletak pada persoalan pengemasan daya tarik wisata. Sejauh mana daya tarik wisata yang ditawarkan memiliki keunikan, keindahan, keaslian, dan nilai yang dapat mempengaruhi kepuasan wisatawan sehingga berdampak pada loyalitas pengunjung (Hermawan, 2017b; Wiradiputra \& Brahmanto, 2016). Selain itu, diperlukan juga pengemasan daya tarik wisata untuk lebih menonjolkan sisi keunikan destinasi sebagai nilai jual (Ainurrahman, 2010). Disertai dengan konsep perencanaan pariwisata yang berkelanjutan yang mantap.

Oleh karena itu, kegiatan pengabdian masyarakat yang befokus pada peningkatan dan pengemasan destinasi wisata Kampung Tulip perlu dilaksanakan agar terwujud destinasi wisata edukasi yang memiliki daya jual dengan menonjolkan sisi keunikan, keindahan, keaslian, dan nilai destinasi wisata edukasi Kampung Tulip yang bertema Edukasi Budaya Belanda.

\section{Metode}

Kegiatan pengabdian masyarakat di destiasi wisata Kampung Tulip difokuskan pada pemberdayaan untuk peningkatan tata kelola destinasi wisata Kampung Tulip yang bertema edukasi. Oleh karena itu, berbagai permasalahan serta dinamika pengelolaan perlu digali terlebih dahulu untuk mendapatkan data yang valid serta langkah rekomendasi yang implementatif.

Permasalahan dikaji menggunakan pendekatan kualitatif. Pendekatan kualitatif dipandang mampu menggali pemaknaan terhadap fenomena secara lebih mendalam (Creswell, 1994). Tahap pencarian data lapangan dilakukan pada tanggal 1 September 2017 sampai dengan tanggal 1 Oktober 2017. Pencarian data dilakukan dengan menggunakan metode observasi dan wawancara terhadap nara sumber meliputi : ketua pengelola destinasi wisata Kampung Tulip, staf pengelola wisata, dan pelaku usaha pendukung. Sedangkan metode analisis data dilakukan dengan cara triangulasi data untuk mendapatkan gambaran valid mengenai kondisi aktual pengelolaan destinasi wisata Kampung Tulip (Moleong, 1995).

Rekomendasi tata kelola wisata edukasi diperoleh melalui strategi boosting, yaitu membuang faktor-faktor yang tidak menguntungkan dan memperpaiki atau menguatkan faktor-faktor yang menjadi keuntungan dalam pengelolaan untuk dapat dilakukan langkah implementasinya (Ashley, 2006).

Kemudian kegiatan pengabdian diakhiri dengan kegiatan seminar dan pelatihan kepada pengelola destinasi wisata Kampung Tulip, disertai 
penyerahan buku panduan pengelolaan wisata edukasi yang dilaksakanan pada tanggal 1 Oktober 2017 sampai dengan 23 Oktober 2017. Sehingga jika digambarkan, alur kegiatan pengabdian masyarakat secara keseluruhan adalah sebagai berikut:

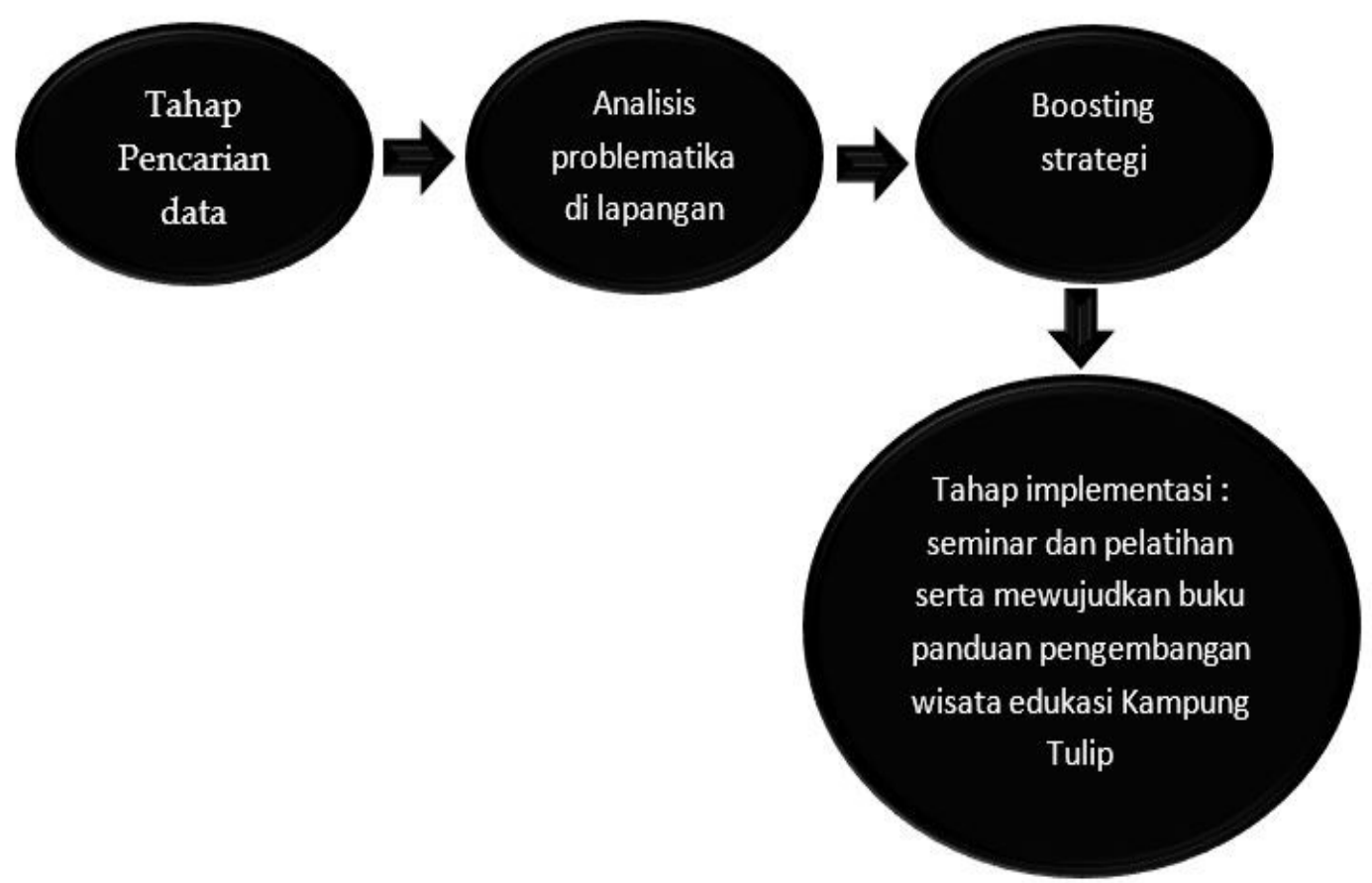

Gambar 1. Alur Kegiatan Pengabdian Masyarakat

\section{Hasil dan Pembahasan}

Destinasi wisata Kampung Tulip, merupakan destinasi wisata edukasi yang terletak di Jalan Banyu Biru H17, Komplek Pasir Pogor, Bandung. Destinasi wisata Kampung Tulip dapat dijangkau dari pusat kota menggunakan angkutan umum. Tarif tiket masuk ke destinasi ditetapkan sebesar Rp.5000 untuk hari kerja (Senin sampai Jumat), dan Rp.7500 untuk hari libur. Sedangkan jam buka pada pukul 09.00 WIB sampai 18.00 WIB.

Destinasi wisata Kampung Tulip menawarkan tema wisata ala Negeri Belanda. Seluruh wahana di destinasi wisata Kampung Tulip dibangun dengan meniru atau replika terhadap kebudayaan dan icon-icon khas Negeri Belanda seperti kincir angin, danau buatan, kotak telepon, rumah khas Negeri Belanda dan lain sebagainya.

Selain itu, destinasi wisata Kampung Tulip dilengkapi dengan berbagai fasilitas seperti galeri Shaby Chik, kolam terapi ikan, arena panahan, kolam memancing untuk anak-anak, dan perahu bebek. Galeri Shaby Chik sendiri merupakan sesuatu yang iconik di destinasi wisata Kampung Tulip. Galeri Shaby Chik berisi berbagai macam furniture yang unik, dan antik. Furniture yang tersedia juga cukup lengkap seperti kursi, jam dinding, cermin, cangkir, mainan anak. pengunjung juga dapat membeli furniture sebagai survenir wisata. 
Destinasi wisata Kampung Tulip juga menawarkan berbagai macam kuliner untuk memanjakan pengunjung dengan harga berkisar Rp.5000 sampai dengan Rp.10.000. aneka macam kulner dijual didalam foodcourt disekitar danau buatan di Kampung Tulip.

Pendidikan dan pariwisata merupakan dua hal yang berbeda, tetapi keduanya dapat saling bersinergi dan saling melengkapi. Proses pendidikan yang dilaksanakan dalam aktivitas wisata merupakan metode pembelajaran yang aktif dan kreatif, serta merupakan alternatif metode belajar yang efektif. Pengertian sederhana wisata edukasi adalah upaya meningkatnya pengetahuan baru melalui kegiatan wisata (Pevzner \& Nikolaeva dalam Wijayanti, 2017).

Melihat fakta dilapangan, destinasi wisata kampung tulip terlihat belum cukup representatif sebagai tempat wisata bertema edukasi Budaya Belanda. Walaupun beberapa wahana telah dibangun menyesuaikan rumah-rumah khas Negeri Belanda, tetapi aktifitas wisata bernuansa edukatif belum begitu terlihat selama masa observasi di lapangan. Padahal, dalam kegiatan taman bertema edukasi, wahana permainan maupun fasilitas pendukung lainnya yang tersedia hendaknya tidak hanya berfungsi sebagai hiburan semata, tetapi diharapkan mengandung unsur edukasi sesuai dengan konsep atau tema yang diangkat.

Kurangnya representasi wisata edukasi dapat dibuktikan pada saat observasi lapangan belum ditemukan papan-papan informasi di destinasi yang mampu menambah pengetahuan wisatawan terhadap karakteristik wahana atau objek di destinasi. Padahal dalam pariwisata dibutuhkan narasi, baik verbal maupun non verbal untuk menghidupkan objek yang menjadi daya tarik. Contoh dalam konteks wisata edukasi Kampung Tulip, alangkah lebih baik jika wahana rumah Belanda dapat disertai dengan papan informasi yang mampu menjelaskan "apa itu namanya" "kenapa bentuknya harus seperti itu""apa fungsinya" "bagaimana membangunya" ataupun dapat berupa informasi-informasi lain yang bernilai edukatif.

Narasi juga dapat diwujudkan secara verbal melalui cerita langsung dari para pemandu wisata. Cerita-cerita ini juga termasuk servis, bahkan termasuk inti dari produk wisata itu sendiri, karena produk wisata termasuk jenis jasa yang waktu konsumsi dan produksinya bersamaan atau simultan untuk mewujudkan pengalaman wisata berkesan yang dapat dinikmati dan bernilai (Hermawan, 2017a).

Aktivitas wisata edukasi hendaknya dapat menjadi sarana bersosialisasi dan menumbuhkan rasa kebanggaan dan kecintaan terhadap budaya dan bangsa (Jafari \& Ritchie, 1981). Wisata edukasi merupakan aktivitas pariwisata yang dilakukan wisatawan dan bertujuan utama memperoleh pendidikan dan pembelajaran. Oleh karena itu, pengelola diharapkan untuk melakukan segmentasi dan diversifikasi bisnis. Destinasi wisata Kampung Tulip dibangun untuk siapa dan bagaimana. Menurut penuturan Bapak Donni selaku narasumber, pengelola mentargetkan pasar wisata kepada anak-anak sekolah dan remaja. Akan tetapi, jika melihat data observasi di lapangan masih terlihat bahwa destnasi wisata Kampung Tulip belum begitu cocok untuk kegiatan wisata edukasi anak-anak. 
Pengembangan wisata juga belum fokus akan ditargetkan untuk siapa, contoh : adanya wahana anak-anak berupa perahu bebek, taman bermain anak, namun disisi lain konsep sarana pendukung kafe dan restoran lebih tepat ditujukan untuk kalangan dewasa.

Tinjauan dalam hal pelayanan, terlihat staf dilapangan belum mampu memberikan pelayanan yang prima. Hal ini terlihat pada saat kunjungan lapangan tidak ditemukan staf yang mampu menyambut wisatawan dengan edukatif. Wisatawan berkualitas tentu menuntut akan perolehan manfaat yang didapat, berupa pengalaman berkualitas berupa peningkatan wawasan baru yang selama berwisata. Kegiatan wisata yang dilakukan wisatawan tentu akan terasa biasa saja tanpa adanya seorang intrepreter yang akan menjelaskan mengenai apa, kenapa, bagaimana fenomena suatu hal sehingga dapat menjadi tambahan ilmu bagi wisatawan.

Oleh karena itu, dalam pengelolaan wisata edukasi dituntut adanya pelayanan yang prima, yaitu pelayanan mampu memenuhi harapan wisatawan akan perolehan pengalaman berharga dan informasi/edukasi terkait destinasi alam yang dikunjunginya. Hal ini dapat diwujudkan jika staf pengelola mampu menjadi interpreter yang mampu menjelaskan destinasi wisata secara ilmiah. Dalam kontek wisata kampung tulip, edukasi yang dimaksud adalah penambahan wawasan dan pemahaman mengenai Negeri Belanda melalui wahana wisata Kampung Tulip. Guna meningkatkan pelayanan prima, dalam kegiatan pengabdian telah merangkup rekomendasi ke dalam buku panduan pengembangan wisata edukasi yang khusus ditujukan untuk pengembangan destinasi wisata kampung tulip. Selain itu, pemberdayaan pengelola melalui seminar dan pelatihan pengelolaan wisata edukasi juga telah dilakukan.

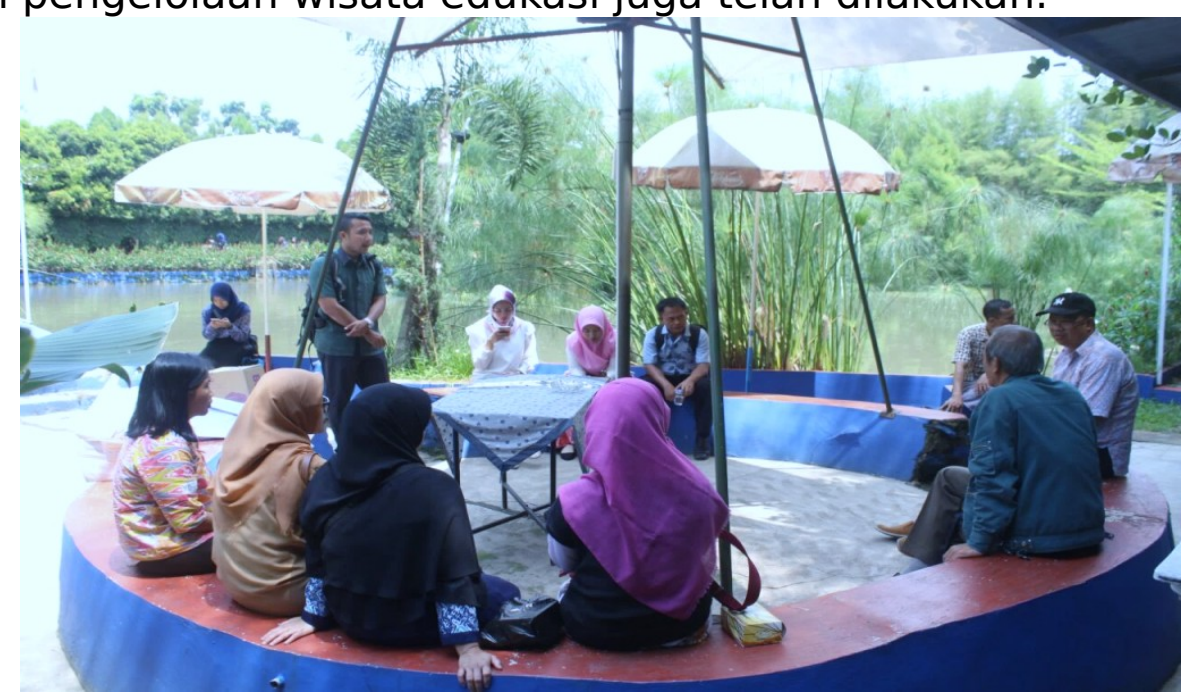

Gambar 2 : Seminar dan pelatihan pengelolaan wisata edukasi 


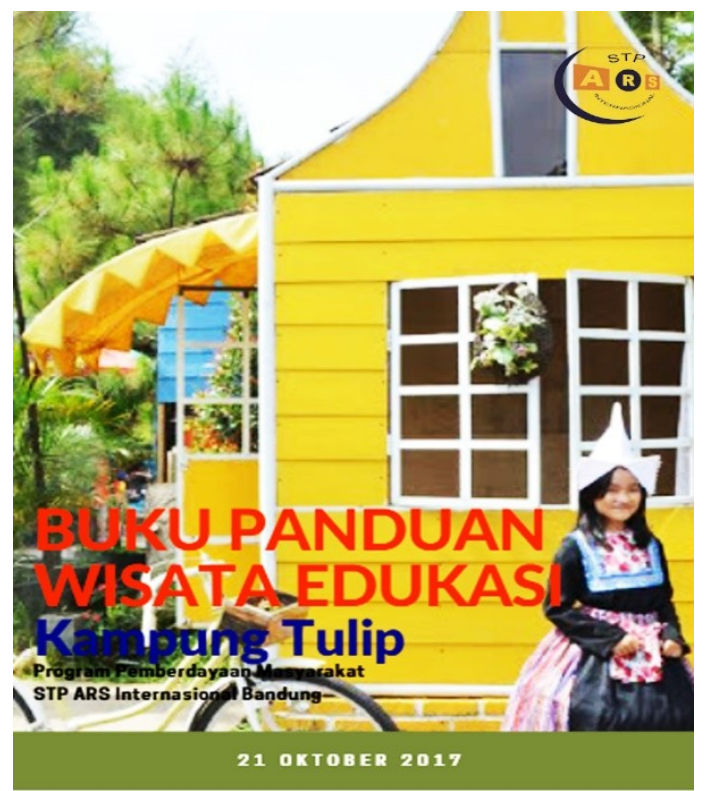

Gambar 3. Luaran pengabdian berupa buku panduan

Selain beberapa poin diatas, mewujudkan pengelolaan pariwisata berkelanjutan merupakan fundamental dalam pengelolaan pariwisata di Kampung Tulip. Rumusan yang lebih spesifik dalam pariwisata berkelanjutan adalah memenuhi kebutuhan wisatawan dan tuan rumah saat ini daerah sekaligus melindungi dan meningkatkan peluang pemenuhan kebutuhan masa depan. Hal ini dipertimbangkan dalam manajerial untuk mengelola semua sumber daya dengan sedemikian rupa, sehingga ekonomi, sosial, dan kebutuhan estetika dapat terpenuhi dengan tetap menjaga nilai-nilai kearifan budaya, perlindungan ekologis penting, keragaman unsur biologi serta sistem pendukung kehidupan lainya (Insula dalam Berno \& Bricker, 2001). Piagam pariwisata berkelanjutan menekankan bahwa pariwisata harus didasarkan pada kriteria yang berkelanjutan yang intinya adalah pembangunan harus didukung secara ekologis dalam jangka panjang dan sekaligus layak secara ekonomi, adil secara etika dan sosial terhadap masyarakat lokal (Arida, 2006). Konsep pariwisata berkelanjutan yaitu : (a) kegiatan kepariwisataan tersebut dapat memberikan manfaat ekonomi terhadap masyarakat setempat, (b) kegiatan kepariwisataan tersebut tidak merusak lingkungan, (c) kegiatan kepariwisataan tersebut bertanggung-jawab secara sosial, dan (d) kegiatan kepariwisataan tersebut tidak bertentangan dengan budaya setempat.

Dalam suatu bisnis tidak tepat jika hanya bertujuan untuk mendapatkan laba sebesar-besarnya dalam jangka pendek, namun kelangsungan bisnis tidak diketahui. Konsep pengembangan dengan berpedoman pada aspek keberlanjutan dapat diupayakan sebagai dasar fundamental dalam pengelolaan destinasi Kampun Tulip jangka panjang.

\section{Simpulan dan Rekomendasi}

Fenomena aktual dilapangan membuktikan bahwa pengembangan Kampung Tulip belum cukup representatif sebagai wisata bertema edukasi 
Budaya Belanda. Walaupun beberapa wahana telah dibangun menyesuaikan rumah-rumah khas Negeri Belanda, tetapi aktifitas wisata bernuansa edukatif belum begitu terlihat selama masa observasi di lapangan.

Oleh karena itu, kegiatan pengabdian masyarakat difokuskan pada pemberdayaan untuk peningkatan tata kelola destinasi wisata edukasi Kampung Tulip. Langkah implementatif yang telah dilakukan meliputi :

Pencarian data lapangan ditujukan untuk menggali akar permasalahan dalam pengembangan destinasi wisata Kampung Tulip melalui observasi dan wawancara dengan pengelola. Permasalahan yang ditemukan dilapangan meliputi : Beberapa wahana telah dibangun menyesuaikan rumah-rumah khas Negeri Belanda tetapi aktifitas wisata bernuansa edukatif belum begitu terlihat selama masa observasi di lapangan, belum ada papan-papan informasi maupun kegiatan pemandu di destinasi yang mampu menambah pengetahuan wisatawan terhadap karakteristik wahana atau objek di destinasi, dalam pengembangan belum terlihat secara jelas segmentasi dan diversifikasi bisnis.

Kegiatan pengabdian masyarakat memberikan rekomendasi pengelolaan melalui seminar dan pelatihan pengelolaan wisata edukasi dan pariwisata berkelanjutan kepada pengelola destinasi wisata Kampung Tulip

Output pengabdian masyarakat termasuk penyediaan buku yang dikhususkan sebagai buku panduan pengembangan wisata edukasi Kampung Tulip.

\section{Daftar Pustaka}

Ainurrahman. (2010). Wisata Berbasis Komunitas. Karsa, 18(2), 136-146.

Ashley, C. (2006). How Can Governments Boost the Local Economic Impacts of Tourism: Options and Tools: Toolkit. SNV Netherlands Development Organization [etc.]. Retrieved from http://www.search4dev.nl/record/284239

Assauri, S. (2012). Strategic Marketing Sustaining Lifetime Customer Value. Jakarta: PT. Raja Grafindo Persada.

Creswell, J. W. (1994). Research Design-Qualitative, Quantitative, and Mixed Method. London: SAGE Publications.

Darsoprajitno, S. (2002). Ekologi Pariwisata. Bandung: Penerbit Angkasa.

Hasan, A. (2013). Marketing dan Kasus-Kasus Pilihan. Yogyakarta: Center for Academic Publishing.

Hermawan, H. (2016). Dampak Pengembangan Desa Wisata Nglanggeran Terhadap Ekonomi Masyarakat Lokal. Jurnal Pariwisata, 3(2), 105-117.

Hermawan, H. (2017a). Pengantar Manajemen Hospitality. Jawa Tengah: 
Penerbit NEM.

Hermawan, H. (2017b). Pengaruh Daya Tarik Wisata, Keselamatan dan Sarana Wisata Terhadap Kepuasan serta Dampaknya terhadap Loyalitas Wisatawan: Studi Community Based Tourism di Gunung Api Purba Nglanggeran. Wahana Informasi Pariwisata: Media Wisata, 15(1), 562-577.

Jafari, J., \& Ritchie, J. R. B. (1981). Toward a Framework for Tourism Education: Problems and Prospects. Annals of Tourism Research, 8(1), 13-34.

Kusumawardani, I. P., \& Hermawan, H. (2017). Kajian Tema Wisata Edukasi di Sindu Kusuma Edupark dari Perspektif Pemasaran Pariwisata. Open Science Framework.

Lukas, S. A. (2008). Theme Park. Reaktion Books.

Matthews, M. D., \& Boyns, T. (2001). A Schedule of the Lyndall Fownes Urwick Archive. The Management College, Henley.

Moleong, L. (1995). Metode penelitian. Bandung: Remaja Rosda Karya.

Prihatno, P. (2010). Memulihkan Citra Daerah Istimewa Yogyakarta untuk Meningkatkan Jumlah Wisatawan. Wahana Informasi Pariwisata: Media Wisata.

Sammeng, A. M. (2001). Cakrawala pariwisata. Balai Pustaka.

Statistik Kepariwisataan. (2015). D.I. Yogyakarta Indonesia: Dinas Pariwisata Daerah Istimewa Yogyakarta. Retrieved from http://visitingjogja.web.id/assets/uploads/files/bank_data/Buku_Statisti k_Kepariwisataan_DIY_2015_05092016040516.pdf, diakses 5 Juni 2017

Undang-Undang Nomor 10 Tahun 2009 Tentang Kepariwisataan, Sekretariat Negara. Jakarta § (2009). Indonesia.

Wijayanti, A. (2017). Analisis Dampak Pengembangan Desa Wisata Kembang Arum Terhadap Perekonomian Masyarakat Lokal. Tesis. Sarjana Wiyata Tamansiswa Yogyakarta.

Wiradiputra, F. A., \& Brahmanto, E. (2016). Analisis Persepsi Wisatawan Mengenai Penurunan Kualitas Daya Tarik Wisata terhadap Minat Berkunjung. Jurnal Pariwisata, 3(2), 129-137.

Yahya, A. (2015). Sambutan Menteri Pariwisata R.I. pada Peringatan World Tourism Day dan Hari Kepariwisataan Nasional. Retrieved from 


\section{JURNAL ABDIMAS BSI}

http://kemenpar.go.id/asp/detil.asp?c $=125 \& i d=2975$ 